\title{
Inquérito sorológico para toxoplasmose e leptospirose em mamíferos selvagens neotropicais do Zoológico de Aracaju, Sergipe ${ }^{1}$
}

\author{
Joubert S. Pimentel ${ }^{2,3,4^{*}}$, Solange M. Gennari ${ }^{5}$, Jitender P. Dubey ${ }^{6}$, Maria F.V. \\ Marvulo $^{7}$, Silvio A. Vasconcellos ${ }^{5}$, Zenaide M. Morais ${ }^{5}$, Jean C.R. Silva ${ }^{3,7}$ e \\ Joaquim Evêncio Neto ${ }^{8}$
}

\begin{abstract}
Pimentel J.S., Gennari S.M., Dubey J.P., Marvulo M.F.V., Vasconcellos S.A., Morais Z.M., Silva J.C.R. \& Evêncio Neto J. 2009. [Serological survey of toxoplasmosis and leptospirosis in neotropical wild mammals from Aracaju Zoo, Sergipe, Brazil.] Inquérito sorológico para toxoplasmose e leptospirose em mamíferos selvagens neotropicais do Zoológico de Aracaju, Sergipe. Pesquisa Veterinária Brasileira 29(12):1009-1014. Empresa de Desenvolvimento Agropecuário de Sergipe, Zoológico do Parque da Cidade, Av. Corinto Leite s/n, Industrial, Aracaju, SE 49067-060, Brazil. E-mail: joubertpimentel@bol.com.br

Modern zoological gardens are institutions to wildlife maintenance, aiming its conservation, the performance of scientific research and leisure, recreation and environmental education activities. The variety of wild species living in conditions different from the one found in its natural habitats represents a propitious environment for diseases spread, specially the zoonotic ones. Due to data shortage and wild mammals' epidemiological relevance both for toxoplasmosis as for leptospirosis, this study aimed to determine the serological survey of toxoplasmosis and leptospirosis in Neotropical wild mammals, from Zoo of Aracaju, Sergipe, Brazil. Blood samples were collected from 32 wild mammals, adults and from both sexes: 14 wild bearded capuchins (Cebus libidinosus), four goldenbellied capuchins (Cebus xanthosternus), three pumas (Puma concolor), one jaguar (Panthera onca), one crab-eating fox (Cerdocyon thous), six crab-eating raccoons (Procyon cancrivorus), two South American coatis (Nasua nasua), and one tayra (Eira barbara). Sera were tested to Toxoplasma gondii antibodies by the modified agglutination test (MAT e"1:25), and by the microscopic seroaglutination test (cut-off e"1:100) using 24 serovar of pathogenic leptospiras and two serovar of saprophyte leptospiras. Antibodies to $T$. gondii were found in 17 of $32(53.1 \%)$ wild mammals, and antibodies to Leptospira spp. were found in 4 of $32(12.5 \%)$ wild mammals. In relation to gender, 9 of $15(60 \%)$ males, and 8 of $17(47.1 \%)$ females had antibodies to Toxoplasma gondii, and 4 of 15 (26.7\%) males had antibodies to Leptospira spp. Considering the origin of the seropositive
\end{abstract}

\footnotetext{
${ }^{1}$ Recebido em 19 de outubro de 2009.

Aceito para publicação em 16 de dezembro de 2009.

${ }^{2}$ Empresa de Desenvolvimento Agropecuário de Sergipe (Emdagro), Zoológico do Parque da Cidade "Governador José Rollemberg Leite". Av. Corinto Leite s/n, Industrial, Aracaju, SE 49067-060, Brasil. *Autor para correspondência: joubertpimentel@bol.com.br

${ }^{3}$ Departamento de Medicina Veterinária, Universidade Federal Rural de Pernambuco (UFRPE), Rua Dom Manoel de Medeiros s/n, Dois Irmãos, Recife, PE 52171-900, Brasil.

${ }^{4}$ Curso de Medicina Veterinária, Faculdade Pio Décimo, Av. Tancredo Neves 5655, Jabotiana, Aracaju, SE 49080-470.

${ }^{5}$ Departamento de Medicina Veterinária Preventiva e Saúde Animal,
}

Faculdade de Medicina Veterinária e Zootecnia, Universidade de São Paulo (USP), Av. Prof. Dr. Orlando Marques de Paiva 87, Cidade Universitária, São Paulo, SP 05508-270, Brasil.

${ }^{6}$ Animal Parasitic Diseases Laboratory, Animal and Natural Resources Institute, Beltsville Agricultural Research Center, United States Department of Agriculture (USDA), Beltsville, MA 20705-2350, USA.

${ }^{7}$ Instituto Brasileiro para Medicina da Conservação - Tríade, Estrada do Encanamento 1752, apto. 1201, Casa Forte, Recife, PE 52070-000, Brasil.

${ }^{8}$ Departamento de Morfologia e Fisiologia Animal, Universidade Federal Rural de Pernambuco (UFRPE), Rua Dom Manoel de Medeiros s/ n, Dois Irmãos, Recife, PE 52171-900. 
animals to $T$. gondii, 8 of 17 (47\%) were born in the zoo, 7 of $17(41.2 \%)$ were from other zoos, and $2(11.8 \%)$ were from the wild. Three of $4(75 \%)$ mammals seropositive to Leptospira spp. were born in zoo, and 1 of $4(25 \%)$ was from the wild. This is the first serological survey of Leptospira spp. in Neotropical primates and carnivores from Northeast zoo of Brazil, and the first time that antibodies to T. gondii and Leptospira spp. (serovar Copenhageni) were observed in the threaten specie of primate golden-bellied capuchins (Cebus xanthosternus) in Aracaju, SE.

INDEX TERMS: Toxoplasma gondii, Leptospira spp., antibody, Primates, Carnivora, captivity.

RESUMO.- Os zoológicos modernos são instituições destinadas à manutenção da fauna selvagem com o objetivo de promover a conservação, pesquisa científica, lazer, recreação e educação ambiental. A ampla variedade de espécies selvagens, vivendo em condições diferentes do seu habitat natural, representa um ambiente propício à disseminação de doenças, muitas delas zoonóticas. Devido à escassez de dados e à relevância dos mamíferos selvagens neste contexto epidemiológico, tanto na toxoplasmose, quanto na leptospirose, foi efetuado o inquérito sorológico para toxoplasmose e leptospirose em mamíferos selvagens neotropicais do Zoológico de Aracaju, Sergipe, Brasil. Para tanto foram colhidas amostras sanguíneas de 32 animais, adultos, de ambos os sexos incluindo: 14 macacos-prego (Cebus libidinosus), quatro macacos-prego-do-peito-amarelo (Cebus xanthosternus), três onças-suçuaranas (Puma concolor), uma onça-pintada (Panthera onca), uma raposa (Cerdocyon thous), seis guaxinins (Procyon cancrivorus), dois quatis (Nasua nasua) e um papa-mel (Eira barbara). Para a pesquisa de anticorpos anti-Toxoplasma gondii foi utilizado o Teste de Aglutinação Modificada (MAT $\geq \square 1: 25$ ) e para pesquisa de anticorpos anti-Leptospira spp. foi utilizado o teste de Soroaglutinação Microscópica (ponto de corte $\geq 1: 100$ ) com uma coleção de antígenos vivos que incluiu 24 variantes sorológicas de leptospiras patogênicas e duas leptospiras saprófitas. Dentre os 32 mamíferos, $17(53,1 \%)$ apresentaram anticorpos anti- $T$. gondii e quatro $(12,5 \%)$ foram positivos para anticorpos anti-Leptospira spp. De acordo com o sexo, $60 \%(9 / 15)$ dos machos e $47,1 \%$ (8/17) das fêmeas foram soropositivos para $T$. gondii e $26,7 \%$ (4/15) dos machos apresentaram anticorpos anti-Leptospira spp. Dos mamíferos que apresentaram anticorpos anti-T. gondii, 47\% (8/17) nasceram no zoológico, 41,2\% (7/17) foram oriundos de outras instituições e dois $(11,8 \%)$ foram provenientes da natureza. Em relação aos quatro mamíferos soropositivos para Leptospira spp., três (75\%) foram procedentes da natureza e um (25\%) nasceu no zoológico. Este foi o primeiro inquérito sorológico de anticorpos anti-Leptospira spp. em primatas e carnívoros neotropicais em um zoológico do Nordeste do Brasil e descreveu pela primeira vez a ocorrência de anticorpos anti- T. gondiie anti-Leptospira spp. com sorovar mais provável Copenhageni no primata ameaçado de extinção macaco-prego-de-peito-amarelo ( $C$. xanthosternus) em Aracaju, SE.

TERMOS DE INDEXAÇÃO: Toxoplasma gondii, Leptospira spp., anticorpos, Primates, Carnivora, cativeiro.

\section{INTRODUÇÃO}

A participação dos animais selvagens como reservatórios ou portadores de zoonoses na natureza e em cativeiro é de grande importância (Acha \& Szyfres 2003). Neste contexto, os zoológicos oferecem oportunidades para o estudo desses animais em situações controladas e são importantes fontes de informação para investigações epidemiológicas de doenças transmissíveis (Munson \& Cock 1993, Thrusfield 2004, Silva et al. 2007). A infecção e a disseminação de patógenos podem ocorrer para os animais selvagens do próprio zoológico, animais sinantrópicos, funcionários e ao público visitante (Silva et al. 2007). Neste ambiente os primatas e os carnívoros selvagens podem vir a se comportar como hospedeiros e reservatórios de agentes etiológicos de zoonoses que incluem a toxoplasmose e a leptospirose (Dubey \& Beattie 1988, Silva et al. 2001, Corrêa et al. 2004, Corrêa 2006).

A toxoplasmose é uma das doenças mais difundidas e prevalentes no mundo, inclusive na fauna selvagem, em vida livre e cativeiro. É causada pelo Toxoplasma gondii e pode acometer praticamente todos os animais endotérmicos, inclusive os seres humanos (Dubey \& Beattie 1988). Uma porcentagem variável de animais sadios e o homem apresentam anticorpos anti- $T$. gondii, contudo, os marsupiais australianos e primatas neotropicais, além de serem altamente suscetíveis, raramente sobrevivem a essa doença (Dubey \& Beattie 1988), sendo desconhecida a razão desta grande suscetibilidade (Cunningham et al. 1992, Epiphanio et al. 2000).

A leptospirose, doença provocada por uma espiroqueta patogênica do gênero Leptospira, reconhecida como um importante problema de saúde pública é considerada a zoonose geograficamente mais difundida no mundo e sua ocorrência é favorecida pelas condições ambientais, em climas tropicais e subtropicais. Várias espécies domésticas e selvagens suscetíveis a esta zoonose podem apresentar infecções subclínicas e tornam-se reservatórias, eliminando as leptospiras na urina (Acha \& Szyfres 2003).

A leptospirose pode ser transmitida por contato com ambientes aquáticos contaminados pela urina dos animais reservatórios, principalmente roedores e carnívoros (Sarkar et al. 2002, Acha \& Szyfres 2003). Investigações sorológicas sobre a ocorrência da leptospirose em animais selvagens têm demonstrado a presença da infecção em roedores, xenartras, carnívoros e artiodátilos de diferentes partes do mundo (Reilly et al. 1968, Michna et al. 1970, Lilenbaum et al. 2002, Corrêa et al. 2004, Esteves et al. 
2005, Corrêa 2006) e sabe-se que os diversos sorovares de leptospiras podem ser carreados por uma grande variedade de hospedeiros (Acha \& Szyfres 2003).

Em zoológicos brasileiros anticorpos anti- $T$. gondii foram pesquisados em diversas espécies de carnívoros e primatas selvagens em São Paulo, SP (Sogorb et al 1972, Sogorb et al 1977, Epiphanio et al 2000), Belo Horizonte, MG (Rivetti Jr. et al. 2008) e em 71 zôos de todo país (Silva et al. 2001). Nos primatas a ocorrência de anticorpos antiToxoplasma gondii variou de 41,7\% a 60\% (Sogorb et al. 1977), nos felídeos de 12,5\% a 94,7\% (Sogorb et al. 1977, Silva et al. 2001, Rivetti Jr. et al. 2008) e nos demais carnívoros de $50 \%$ a $87,5 \%$ (Sogorb et al. 1977). Em outros países, anticorpos anti-T. gondii em primatas e carnívoros selvagens neotropicais foram investigados por Gorman et al. (1986), Choi et al. (1987), Spencer et al. (2003), Sedlák \& Bártová (2006) e de Camps et al. (2008).

No Brasil as investigações sorológicas sobre a leptospirose em animais selvagens de cativeiro têm apresentado resultados variáveis, sendo realizadas nos zoológicos do Rio de Janeiro, RJ (Lilenbaum et al. 2002), São Paulo, SP (Corrêa et al. 2004), Foz do Iguaçu, PR (Guerra Neto et al. 2004) e Uberaba, MG (Esteves et al. 2005). Os sorovares de Leptospira spp mais prováveis encontrados em primatas foram Castellonis, Copenhageni, Grippotyphosa (Lilenbaum et al. 2002, Corrêa et al. 2004), em canídeos foram Canicola, Castellonis, Copenhageni, Cynopteri, Grippotyphosa e Mini (Lilenbaum et al. 2002, Corrêa et al. 2004, Esteves et al. 2005), em felídeos foram Andamana, Autumnalis, Bratislava, Butembo, Canicola, Castellonis, Grippotyphosa, Hardjo, Icterohaemorrhagiae, Patoc e Pomona (Corrêa et al. 2004, Guerra Neto et al. 2004, Esteves et al. 2005) e em procionídeos e mustelídeos foi o sorovar Copenhageni (Lilenbaum et al. 2002).

Levando-se em consideração a ausência de informação sobre o papel representado pelos mamíferos selvagens neotropicais do zoológico de Aracaju, SE, como reservatórios de Toxoplasma gondii e Leptospira spp., foi delineado o presente estudo que teve por objetivo realizar inquérito sorológico para toxoplasmose e leptospirose em primatas e carnívoros selvagens neotropicais mantidos em cativeiro em tal Instituição.

\section{MATERIAL E MÉTODOS}

O estudo foi desenvolvido no Zoológico do Parque da Cidade “Governador José Rollemberg Leite" em Aracaju, SE (10\%53’04 77"S / 37\%03'23 32" W). Este Parque está localizado na Área de Proteção Ambiental (APA) Morro do Urubu. Todos os animais selvagens são nativos da fauna brasileira, com exceção do casal de leões (Panthera leo).

Entre julho e novembro de 2008 foram colhidas amostras sanguíneas de 32 mamíferos neotropicais (15 machos e 17 fêmeas), adultos, sendo: 14 macacos-prego (Cebus libidinosus), quatro macacos-prego-do-peito-amarelo (Cebus xanthosternus), três onças-suçuaranas (Puma concolor), uma onça-pintada (Panthera onca), uma raposa (Cerdocyon thous), seis guaxinins (Procyon cancrivorus), dois quatis (Nasua nasua) e um papamel (Eira barbara).
Os animais foram contidos de forma física (cebídeos) ou química (carnívoros selvagens), esta última com cloridrato de cetamina associado ao cloridrato de xilazina nas dosagens de $10 \mathrm{mg} / \mathrm{kg}$ cetamina $+1 \mathrm{mg} / \mathrm{kg}$ xilazina (onça-suçuarana e papa$\mathrm{mel}$ ), $7-8 \mathrm{mg} / \mathrm{kg}$ cetamina + 0,5-1,0 mg/kg xilazina (onça-pintada), $7-10 \mathrm{mg} / \mathrm{kg}$ cetamina $+0,3-0,5 \mathrm{mg} / \mathrm{kg}$ xilazina (raposa) e 8-10mg/ $\mathrm{kg}$ cetamina $+1 \mathrm{mg} / \mathrm{kg}$ xilazina (guaxinim e quati) (Nunes et al 2006). No momento da contenção os mamíferos foram avaliados clinicamente (Corrêa 2006, Silva 2006).

As amostras sanguíneas colhidas por venopunção foram dessoradas e o soro foi dividido em alíquotas em microtubos de polipropileno e conservados a $-20^{\circ} \mathrm{C}$ até o exame laboratorial.

Para a pesquisa de anticorpos anti-Toxoplasma gondii foi utilizado o Teste de Aglutinação Modificada (MAT) utilizando taquizoítos inativados pela formalina e 2-mercaptoetanol (Dubey \& Desmonts 1987). Os soros foram examinados nas diluições de 1:25, 1:50 e 1:500. Os títulos corresponderam à maior diluição que apresentou aglutinação. Os animais com título e"25 foram considerados como submetidos a uma infecção passada pelo T. gondii (Silva et al. 2001, Dubey et al. 2004). Soros controles positivos e negativos foram incluídos em cada teste.

A pesquisa de anticorpos anti-Leptospira spp. foi realizada pela microtécnica de soroaglutinação microscópica (Cole et al. 1973), com uma coleção de antígenos vivos que incluiu 24 sorovares de leptospiras patogênicas: Australis, Bratislava, Autumnalis, Butembo, Castellonis, Bataviae, Canicola, Whitcombi, Cynopteri, Grippotyphosa, Hebdomadis, Copenhageni, Icterohaemorrhagiae, Javanica; Panama; Pomona; Pyrogenes; Hardjo (Hardjoprajitno); Wolffi; Hardjo (Hardjobovis), Shermani, Tarassovi, Patoc e Sentot. Os antígenos foram mantidos em meio líquido de EMJH modificado (Alves et al. 1996). Os soros foram triados na diluição de 1:100 e os que apresentaram reação na triagem foram titulados com os respectivos antígenos reacionantes em uma série geométrica de diluições de razão dois. O título foi considerado a recíproca da maior diluição em que foi observado $50 \%$ de leptospiras aglutinadas por campo microscópico.

As proporções de animais soro reagentes foram calculadas por espécie animal e total, com intervalo de confiança de $95 \%$ com o emprego do Programa EPI Info 6.0.

O projeto foi submetido e aprovado pelo Instituto Chico Mendes de Conservação da Biodiversidade (ICMBio) licença ambiental Número 15726-2.

\section{RESULTADOS}

Dos 32 animais examinados, 17 (53,1\%) apresentaram anticorpos para Toxoplasma gondii e quatro (12,5\%) reagiram para Leptospira spp. As proporções de mamíferos selvagens neotropicais soro-reatores e os respectivos intervalos de confiança de $95 \%$ estão apresentados nos Quadros 1 e 2, respectivamente.

De acordo com o sexo, $60 \%$ (9/15) dos machos e $47,1 \%$ (8/17) das fêmeas foram soropositivos para anticorpos anti- $T$. gondii e $26,7 \%(4 / 15)$ dos machos apresentaram anticorpos anti-Leptospira spp. Com relação à procedência dos animais positivos a T. gondii, 47\% (8/17) nasceram no próprio zoológico, $41,2 \%$ (7/17) eram oriundos de outras instituições e dois $(11,8 \%)$ eram provenientes da natureza. Dos quatro mamíferos soropositivos para Leptospira spp., três $(75 \%)$ eram procedentes da natureza e um (25\%) nasceu no zoológico. 
Quadro 1. Presença e título de anticorpos anti-Toxoplasma gondii em mamíferos selvagens neotropicais do Zoológico de Aracaju, SE

\begin{tabular}{|c|c|c|c|c|c|c|}
\hline \multirow[t]{2}{*}{ Espécies } & \multicolumn{2}{|c|}{ Soros } & \multirow[t]{2}{*}{$\%$ [IC 95\%] } & \multicolumn{3}{|c|}{ Títulos de anticorpos (MAT b) } \\
\hline & Positivos $^{a}$ & Examinados & & $<25$ & 50 & 3500 \\
\hline Macaco-prego (Cebus libidinosus) & 3 & 14 & $21,4[4,66-50,80 \%]$ & 11 & - & 3 \\
\hline $\begin{array}{l}\text { Macaco-prego-peito-amarelo } \\
\text { (Cebus xanthosternus) }\end{array}$ & 3 & 4 & $75[19,41-99,37 \%]$ & 1 & - & 3 \\
\hline Onça-suçuarana (Puma concolor) & 3 & 3 & $100[29,24-100,0 \%]$ & - & 2 & 1 \\
\hline Onça-pintada (Panthera onca) & 1 & 1 & $100[2,5-100,0 \%]$ & - & 1 & - \\
\hline Raposa (Cerdocyon thous) & 0 & 1 & $0[0,00-97,5 \%]$ & 1 & - & - \\
\hline Guaxinim (Procyon cancrivorus) & 4 & 6 & $66,7[2,28-95,67 \%]$ & 2 & 3 & 1 \\
\hline Quati (Nasua nasua) & 2 & 2 & $100[15,81-100,0 \%]$ & - & 2 & - \\
\hline Papa-mel (Eira barbara) & 1 & 1 & $100[2,5-100,0 \%]$ & - & 1 & - \\
\hline Total & 17 & 32 & $53,1[34,74-70,91]$ & 15 & 9 & 8 \\
\hline
\end{tabular}

a Positivo: título ${ }^{325 ;}{ }^{b}$ MAT $=$ Modified Agglutination Test .

Quadro 2. Prováveis variantes sorológicas e títulos de anticorpos anti-Leptospira spp em mamíferos selvagens neotropicais do Zoológico de Aracaju, SE

\begin{tabular}{|c|c|c|c|c|c|}
\hline \multirow[t]{2}{*}{ Mamíferos selvagens } & \multicolumn{2}{|c|}{ Soros } & \multirow[t]{2}{*}{$\%$ [IC 95\%] } & \multirow{2}{*}{$\begin{array}{l}\text { Prováveis } \\
\text { sorovares }\end{array}$} & \multirow[t]{2}{*}{ Títulos } \\
\hline & Positivos $^{a}$ & Examinados & & & \\
\hline Macaco-prego (Cebus libinosus) & 1 & 14 & $7,1[0,18-33,87 \%]$ & Copenhageni & 400 \\
\hline $\begin{array}{l}\text { Macaco-prego-peito-amarelo } \\
\text { (Cebus xanthosternus) }\end{array}$ & 1 & 4 & $25,0[0,63-80,58 \%]$ & Copenhageni & 800 \\
\hline Onça-suçuarana (Puma concolor) & 0 & 3 & $0[0,00-70,76 \%]$ & - & - \\
\hline Onça-pintada (Panthera onca) & 0 & 1 & $0[0,00-97,50 \%]$ & - & - \\
\hline Raposa (Cerdocyon thous) & 1 & 1 & $100[2,5-100,0 \%]$ & Copenhageni & 400 \\
\hline Guaxinim (Procyon cancrivorus) & 1 & 6 & $16,7[0,42-64,12 \%]$ & Copenhageni & 400 \\
\hline Quati (Nasua nasua) & 0 & 2 & $0[0,00-84,19 \%]$ & - & - \\
\hline Papa-mel (Eira barbara) & 0 & 1 & $0[0,00-97,5 \%]$ & - & - \\
\hline Total & 4 & 32 & $12,5[3,51-28,99 \%]$ & - & - \\
\hline
\end{tabular}

Na avaliação clínica os mamíferos apresentavam-se saudáveis sem sinais clínicos de toxoplasmose e leptospirose.

\section{DISCUSSÃO}

Não foi possível a determinação das vias de transmissão e fontes de infecção relacionadas à presença de animais positivos para Toxoplasma gondii no zoológico de Aracaju, SE. No entanto, para os carnívoros selvagens e os primatas de hábito carnívoro, a ingestão de carnes cruas contendo bradizoítos em cistos teciduais, de oocistos em alimentos e água contaminados ou no ambiente podem ter sido as vias de transmissão mais relacionadas a este agente. Os resultados positivos encontrados para os primatas neotropicais poderiam também ser atribuídos à mudança de comportamento destes animais decorrente ao cativeiro, pois em tal condição passam maior parte do dia no chão dos recintos, o que poderia propiciar a ingestão de oocistos de $T$. gondii o que não ocorre na natureza em que habitam as árvores e raramente vão ao solo (Silva 2006).

Os exames para leptospirose encontraram reações para o sorovar Copenhageni, nos primatas macaco-prego e macaco-prego-peito-amarelo, bem como nos carnívoros raposa e guaxinim. Este sorovar é um membro do sorogrupo Icterohaemorragiae que tem como hospedeiros de manutenção os roedores sinantrópicos (Faine et al. 1999) e su- gere a presença de roedores, particularmente a ratazana (Rattus norvergicus) como possível reservatório no ambiente do Zoológico de Aracaju, Sergipe. Lilenbaum et al. (2002), no zoológico do Rio de Janeiro encontraram o predomínio de reações para este sorovar em 93,2\% (27/29) dos diferentes animais selvagens examinados o que concorda com o obtido no presente estudo.

O encontro de primatas reagindo para o sorovar Copenhageni verificado no presente trabalho e em particular a constatação de um macaco-prego-do-peito-amarelo, animal classificado na lista de espécies ameaçadas de extinção, apresentando reação para Leptospira spp, sorovar Copenhageni é inédito. Lilenbaum et al. (2002) e Corrêa et al. (2004) observaram reações para este sorovar em outros primatas neotropicais.

A despeito do sorogrupo Icterohaemorragiae da Leptospira interrogans ter os roedores sinantrópicos como principais hospedeiros de manutenção, as reações para o sorovar Copenhageni têm sido encontradas em diversos animais selvagens. No Brasil, já foram observadas reações para este sorovar em javalis (Sus scrofa scrofa) (Marchiori Filho et al. 2002), capivaras (Hydrochaeris hydrochaeris) (Milagres 2004) e em veado-campeiro (Ozotocerus bezoarticus) (Girio et al. 2004) e, portanto, outras espécies também podem estar participando da cadeia epidemiológica deste sorovar. Destaca-se que no Brasil este sorovar 
tem sido o principal responsável pelos casos de leptospirose em seres humanos (Sakata et al. 1992).

Não foi possível também a caracterização efetiva das fontes de infecção e vias de transmissão de Leptospira spp no zoológico de Aracaju, SE. Contudo a presença de ratazanas ( $R$. norvegicus) em tocas na ilha dos macacospregos poderia ser a responsável pela contaminação do ambiente. De fato um dos macacos da ilha foi soropositivo. Na Fundação Parque Zoológico de São Paulo o isolamento de $L$. interrogans e a reação positiva para o sorovar Icterohaemorrhagiae em $42,8 \%$ (3/7) de ratazanas capturadas indicaram que este animal sinantrópico foi o maior responsável pela manutenção do agente no zoológico (Corrêa et al. 2004). Também, este mesmo sorovar foi encontrado em 1/27(3\%) rato-de-telhado (Rattus rattus) no zoológico de Uberaba, MG, Brasil (Esteves et al. 2005).

Com relação à procedência dos mamíferos selvagens neotropicais do zoológico de Aracaju, SE, a ocorrência de anticorpos anti- $T$. gondii em 47\% (8/17) e a ocorrência de anticorpos anti-Leptospira spp. em 25\% (1/4) nos mamíferos que nasceram no zoológico indica que estes animais se infectaram neste ambiente. Desta forma, medidas de biossegurança para o controle e erradicação da toxoplasmose e leptospirose neste zoológico devem ser implementadas (Corrêa et al. 2004, Corrêa 2006, Silva 2006). Já no relativo aos mamíferos selvagens oriundos de outras instituições e dos provenientes da natureza não se pode afirmar que os mesmos tenham se infectado no zoológico de Aracaju, em outro zoológico ou na natureza, pois os animais estavam alojados no zoológico de Aracaju há mais de um ano.

\section{CONCLUSÕES}

A ocorrência de anticorpos anti-Toxoplasma gondii e anti-Leptospira spp., sorovar mais provável Copenhageni na espécie de primata neotropical ameaçada de extinção Cebus xanthosternus (macaco-prego-de-peito-amarelo) em Aracaju, SE, Brasil, foi descrita pela primeira vez.

A prevenção da toxoplasmose e leptospirose em zoológicos deve apoiar-se em mudanças de hábitos no manejo sanitário, na capacitação de pessoal, na vigilância e no monitoramento sorológico rotineiro nos animais selvagens.

Agradecimentos.- Ao Departamento de Medicina Veterinária, UFRPE, ao Departamento de Medicina Veterinária Preventiva e Saúde Animal, FMVZ-USP, à Empresa de Desenvolvimento Agropecuário de Sergipe (EMDAGRO), à equipe técnica e aos mamíferos selvagens neotropicais do zoológico do Parque da Cidade, que foram à essência deste estudo e que, verdadeiramente deram sangue para tudo acontecer.

\section{REFERÊNCIAS}

Acha P.N. \& Szyfres B. 2003. Zoonosis y Enfermedades Transmisibles Comunes al Hombre y a los Animales: Bacteriosis y Micosis. Vol.1. $3^{\text {a }}$ ed. Publicación Científica no.580, OPS, Washington, p.175-185.

Alves C.J., Vasconcellos S.A., Camargo C.R.A. \& Morais Z.M. 1996. Influência de fatores ambientais sobre a proporção de caprinos sororeatores para a leptospirose em cinco centros de criação do Estado da Paraíba, Brasil. Arqs Inst. Biológico, São Paulo, 63:11-18.
Choi W.Y., Yoo J.E., Nam H.W., Oh C.Y., Kim S.W., Katakura K. \& Kobayashi A. 1987. Toxoplasma antibodies by indirect latex agglutination tests in zoo animals. Korean J. Parasitol. 25:13-23.

Cole J.R., Sulzer C.R. \& Pursell A.R. 1973. Improved microtechnique for the leptospiral microscopic agglutination test. Appl. Microbiol. 25:976-986.

Corrêa S.H.R. 2006. Leptospirose, p.736-741. In: Cubas Z.S., Silva J.C.R. \& Catão-Dias J.L. (Eds), Tratado de Animais Selvagens: medicina veterinária. Roca, São Paulo.

Corrêa S.H.R., Vasconcellos S.A., Teixeira A.A., Dias R.A., Guimarães M.A.B.V., Ferreira F. \& Ferreira Neto, J.S. 2004. Epidemiologia da leptospirose em animais silvestres na Fundação Parque Zoológico de São Paulo. Braz. J. Vet. Res. Anim. Sci. 41:189-193.

Cunningham A.A., Buxton D. \& Thompson K.M. 1992. An epidemic of toxoplasmosis in a captive colony of squirrel monkeys (Saimiri sciureus). J. Comp. Pathol. 107:207-219.

De Camps S., Dubey J.P. \& Saville W.J.A. 2008. Seroepidemiology of Toxoplasma gondii in zoo animals in selected zoos in the Midwestern United States. J. Parasitol. 94:648-653.

Dubey J.P. \& Beattie C.P. 1988. Toxoplasmosis of Animals and Man. CRC Press, Boca Raton. 220p.

Dubey J.P. \& Desmonts G. 1987. Serologic responses of equids fed Toxoplasma gondii oocysts. Equine Vet. J. 19:337-339.

Dubey J.P., Graham D.H., De Young R.W., Dahl E., Eberhard M.L., Nace E.K., Won K., Bishop H., Punkosdy G., Sreekumar C., Vianna M.C.B., Shen S.K., Kwok O.C.H., Sumners J.A., Demarais S., Humphreys J.G. \& Lehmann T. 2004. Molecular and biologic characteristics of Toxoplasma gondii isolates from wildlife in the United States. J. Parasitol. 90:67-71.

Epiphanio S., Guimarães M.A.B.V., Fedullo D.L., Corrêa S.H.R. \& CatãoDias J.L. 2000. Toxoplasmosis in golden-headed lion tamarins (Leontopithecus chrysomelas) and emperor marmosets (Saguinus imperator) in captivity. J. Zoo Wildl. Med. 31:231-235.

Esteves F.M., Guerra-Neto G., Girio R.J.S., Silva-Vergara M.L. \& Carvalho A.C.F.B. 2005. Detecção de anticorpos para Leptospira spp. em animais e funcionários do Zoológico Municipal de Uberaba, MG. Arqs Inst. Biológico, São Paulo, 72:283-288.

Faine S., Adler B., Bolin C. \& Perolat P. 1999. Leptospira and Leptospirosis. $2^{\text {nd }}$ ed. Monash University Print Services, Melbourne. 272p.

Girio R.J.S., Pereira F.L.G, Marchiori Filho M., Mathias L.A., Herreira R.C.P., Alessi A.C. \& Girio T.M.S. Pesquisa de anticorpos contra Leptospira spp. em animais silvestres e em estado feral da região de Nhecolândia, Mato Grosso do Sul, Brasil: utilização da técnica de imunohistoquímica para detecção do agente. Ciência Rural 34:165169.

Gorman T.R., Riversos V., Alcaíno H.A., Salas D.R. \& Thiermann E.R. 1986. Helminthiasis and toxoplasmosis among exotic mammals at the Santiago Nacional Zoo. J. Am. Vet. Med. Assoc. 189:1068-1070.

Guerra Neto G., Girio R.J.S., Andrade T.M., Koproski L.P., Moraes W. \& Santos L.C. 2004. Ocorrência de anticorpos contra Leptospira spp. em felídeos neotropicais pertencentes ao Criadouro de Animais Silvestres da Itaipu Binacional e ao Zoológico Municipal Bosque Guarani, Foz do Iguaçu Estado do Paraná. Ars Vet. 20:75-80.

Lilenbaum W., Monteiro R.V., Ristow P., Fraguas S., Cardoso V.S. \& Fedullo L.P.L. 2002. Leptospirosis antibodies in mammals from Rio de Janeiro Zoo, Brazil. Res. Vet. Sci. 73:319-321.

Marchiori Filho M., Girio R.J.S., Lui J.F., Mathias L.A. \& Brasil A.T.R. 2002. Estudo sorológico para leptospirose em populações de diferentes grupos genéticos de javalis (Sus scrofa scrofa, Linnaeus, 1758) dos estados de São Paulo e Paraná. Arqs Inst. Biológico, São Paulo, 69:9-15.

Michna S.W. \& Campbel R.S.F. 1970. Leptospirosis in wild animals. J. Comp. Pathol. 8:101-106.

Milagres B.S. 2004. Perfil sorológico de algumas infecções capivara 
(Hydrochaeris hydrochaeris) capturadas nos Estados de São Paulo e Minas Gerais, Brasil. Dissertação de Mestrado em Medicina Veterinária, Universidade Federal de Viçosa, Viçosa, MG. 65p.

Munson L. \& Cook R.A. 1993. Monitoring, investigation and surveillance of diseases in captive wildlife. J. Zoo Wildl. Med. 24:281-290.

Nunes A.L.V., Cruz M.L. \& Cortopassi S.R.G. 2006. Anestesiologia, p.1040-1067. In: Cubas Z.S., Silva J.C.R. \& Catão-Dias J.L. (Eds), Tratado de Animais Selvagens: medicina veterinária. Roca, São Paulo.

Rivetti Jr A.V., Caxito F.A., Resende M. \& Lobato Z.I.P. 2008. Avaliação sorológica para Toxoplasma gondii pela imunofluorescência indireta e detecção do vírus da imunodeficiência felina pela nested PCR em felinos selvagens. Arq. Bras. Med. Vet. Zootec. 60:12811283.

Sakata E.E., Yasuda P.H., Romero E.C., Silva M.V. \& Lomar A.V. 1992. Sorovares de Leptospira interrogans isolados de casos de leptospirose humana em São Paulo, Brasil. Revta Inst. Med. Trop., São Paulo, 34:217-221.

Sarkar V., Nascimento S.F, Barbosa R, Martins R., Nuevo H., Kalafanos I., Grunstein I., Flannery B., Dias J., Riley L.W., Reis M.G. \& Ko A.I. 2002. Population-based case-control investigation of risk factors for leptospirosis during in urban epidemic. Am. J. Trop. Med. Hyg. 66:605610.

Sedlák E. \& Bártová E. 2006. Seroprevalences of antibodies to Neos- pora caninum and Toxoplasma gondii in zoo animals. Vet. Parasitol. 136:223-231.

Silva J.C.R. 2006. Toxoplasmose, p.768-784. In: Cubas Z.S., Silva J.C.R. \& Catão-Dias J. L. (Eds), Tratado de Animais Selvagens: medicina veterinária. Roca, São Paulo.

Silva J.C.R., Marvulo M.F.V., Dias R.A., Ferreira F., Amaku M., Adania C.H. \& Ferreira Neto J.S. 2007. Risk factors associated with seropositivity to Toxoplasma gondii in captive Neotropical felids from Brazil. Prev. Vet. Med. 78:286-295.

Silva J.C.R., Ogassawara S., Adania C.H., Ferreira F., Gennari S.M., Dubey J.P. \& Ferreira-Neto J. S. 2001. Seroprevalence of Toxoplasma gondii in captive Neotropical felids from Brazil. Vet. Parasitol. 102:217-224.

Sogorb F., Jamra L.F. \& Guimaraes E.C. 1977. Toxoplasmose em animais de São Paulo, Brasil. Revta Inst. Med. Trop. São Paulo 19:191-194.

Sogorb F., Jamra L.F., Guimarães E.C. \& Deane M.P. 1972. Toxoplasmose espontânea em animais domésticos e silvestres, em São PauIo, Brasil. Revta Inst. Med. Trop., São Paulo, 14:314-320.

Spencer J.A., Higginbotham M.J. \& Blagburn B.L. 2003. Seroprevalence of Neospora caninum and Toxoplasma gondii in captive and freeranging nondomestic felids in the United States. J. Zoo Wildl. Med. 34:246-249.

Thrusfield M. 2004. Epidemiologia Veterinária. $2^{\underline{a}}$ ed. Roca, São Paulo, p.185. 